\title{
Applications of Bolm's Ligand in Enantioselective Synthesis
}

\author{
Eva Bednářová ${ }^{(0,}$, Štefan Malatinec and Martin Kotora * \\ Department of Organic Chemistry, Faculty of Science, Charles University, Albertov 6, 12843 Praha 2, \\ Czech Republic; eva.bednarova@natur.cuni.cz (E.B.); malatinecstefan@gmail.com (Š.M.) \\ * Correspondence: kotora@natur.cuni.cz; Tel.: +420-221-951-058
}

Received: 3 February 2020; Accepted: 17 February 2020; Published: 20 February 2020

check for updates

\begin{abstract}
One pathway for the preparation of enantiomerically pure compounds from prochiral substrates is the use of metal complex catalysis with chiral ligands. Compared to the other frequently used chiral ligands, chiral 2,2'-bipyridines have been underexploited, despite the data indicating that such ligands have considerable potential in synthetic chemistry. One of those is the so-called Bolm's ligand, a compound possessing chiral alcohol moieties in the side chains attached to the $2,2^{\prime}$-bipyridine scaffold. Various metal salts have been used in combination with Bolm's ligand as potent catalysts able to bring about enantioselective alkylations, allylations, conjugate additions, desymmetrization of meso-epoxides, aldol reactions, etc. This review aims to summarize Bolm's ligand applications in the area of enantioselective synthesis over the last three decades since its preparation.
\end{abstract}

Keywords: catalysis; enantioselectivity; synthesis; bipyridine

\section{Introduction}

Growing demands for chiral compounds in pharmaceutical, agrochemical, and other fields of chemical industry have resulted in the search for new, more selective, economical, and environmentally friendly approaches in asymmetric synthesis. In this respect, enantioselective catalysis by means of chiral metal complexes is one such approach. Endeavors in this field are closely associated with the development of new chiral ligands that are able to modulate the reactivity of the metal center in such a way that the prochiral compound is selectively transformed into one out of two possible enantiomers. In comparison to other classes of chiral ligands based on phosphines, salens, oxazolines, or the tartrate scaffolds, chiral 2,2'-bipyridines have attracted comparatively little attention.

Their low popularity probably stems from the lack of suitable synthetic methods furnishing substituted chiral 2,2'-bipyridines. Fine-tuning of such bipyridines by judicious substitution could improve the activity of the whole metal-ligand complex catalyst and thus provide chiral products of catalyzed reactions in higher yields and enantiopurities. The development of methods providing such substituted bipyridines is thus desirable.

In general, 2,2'-bipyridines have found application in various fields of chemistry-such as macromolecular chemistry [1], supramolecular chemistry [2], material chemistry [3], photochemistry [4], electrochemistry [5] - and, due to their extraordinary coordination properties, as ligands in metal-catalyzed reactions [6]. Compared to other commonly used ligands, such as phosphines and cyclopentadienes, they are remarkably stable towards both air and moisture, which is advantageous during their preparation, handling, and storage. The presence of two nitrogen atoms in an almost ideal configuration to form the five-membered chelate ring with a metal center results in remarkably stable complexes even with labile metal sources. In addition, the derivatization of one of the other eight carbon atoms, thanks to the change of steric and electronic properties, enables the achievement of the optimal behavior of the whole complex for the appropriate application [7]. 
The substitution of the 2,2'-bipyridine scaffold in the positions 6 and $6^{\prime}$ causes the most significant changes in the coordination abilities of the corresponding bipyridine. The bulky substituents increase steric hindrance, which hampers the accessibility of the two nitrogen atoms towards coordination. On the other hand, a finely tuned substituent with atoms capable of chelation of the metal center can stabilize the whole complex through the creation of multicoordinated complexes (Figure 1). Moreover, the insertion of a side chain bearing the center of chirality allows for the control of the stereochemistry around the metal center and thus expands the application scope to asymmetric catalysis. During the last decades, chiral 2,2'-bipyridines have found application in the cyclopropanation of alkenes, alkylation and allylation of aldehydes, hydrogenation and hydrosilylation of carbonyl compounds, alkylation and oxidation of allylic position, aldol type reactions, etc. [8].

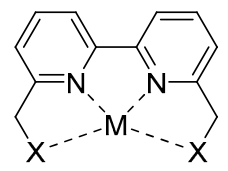

$\mathrm{X}=\mathrm{N}, \mathrm{O}$, etc.

$\mathrm{M}=$ metal

Figure 1. Multidentate chelation of metal center by 6,6' -substituted 2,2' -bipyridine.

Substituted 2,2'-bipyridines can be divided into two groups: those with $\mathrm{C}_{2}$ - and $\mathrm{C}_{1}$-symmetry elements. Examples of bipyridines possessing a central, axial, planar, and helical element of chirality can be found, as well as those with more than one element of chirality. However, the most significant are $2,2^{\prime}$-bipyridines with $\mathrm{C}_{2}$-symmetry element.

\section{Bolm's Ligand}

\subsection{Bolm's Ligand Properties and Synthesis}

The most frequently used chiral 2,2'-bipyridine ligand, and perhaps the most versatile one used in metal-catalyzed asymmetric reactions, is Bolm's ligand 1 . It has $C_{2}$-symmetry and possesses the bipyridine scaffold with two side chains with chiral alcohols moieties in positions 6 and 6' (Figure 2). Due to its ability to chelate several metallic ions, Bolm's ligand $\mathbf{1}$ has found application in various types of metal-catalyzed enantioselective reactions.

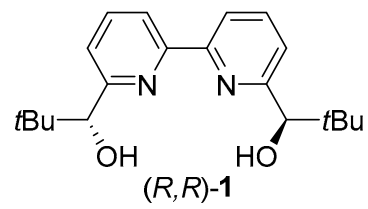

Figure 2. Bolm's ligand $(R, R)-\mathbf{1}$.

$(R, R)-1$ was designed and synthesized by Bolm et al. in 1990 [9], and a more detailed synthesis was then described in 1992 by the same authors [10]. The synthesis started from commercially available 2,6-dibromopyridine and was accomplished in four steps. Later, the synthesis was improved by Kobayashi et al., who developed an alternative method for its preparation [11].

NMR studies of Bolm's ligand $\mathbf{1}$ in a solution, as well as a single crystal X-ray diffraction analysis, confirmed the presence of the transoid arrangement of nitrogen atoms in pyridine rings. Nevertheless, the nitrogen atoms can also adopt, due to the free rotation around the C2-C2' bond, a cisoid arrangement, which is actually the favorable conformation in its complexes with metal salts. Usually, both nitrogen atoms are coordinated to the same metal center [10].

The presence of two nitrogen atoms in the pyridine rings and two oxygen atoms in the side chains indicates that Bolm's ligand could theoretically form mono-, bi-, tri- or tetracoordinated metal complexes. While mono- and bicoordinated complexes of Bolm's ligand are not known, the formation of the respective tri- and tetracoordinated complexes have been observed. The tricoordinated 
complexes of $\mathbf{1}$ are formed with $\mathrm{Zn}$ (II) bromide, as well as with $\mathrm{Cu}(\mathrm{II})$ bromide, and the complexes adopt a square-pyramidal arrangement where nitrogen and oxygen atoms of $\mathbf{1}$ are attached to the same metal center [12,13]. On the other hand, the Fe(II)- [14-16], Sc(III)- [17], Bi(III)- [18], and In(III)-complexes [19] have a pentagonal bipyramidal arrangement, in which both nitrogen atoms of the bipyridine scaffold and both oxygen atoms of the hydroxy groups are coordinated in the metal center in the tetracoordinated manner. The four atoms of $\mathbf{1}(\mathrm{N}, \mathrm{N}, \mathrm{O}, \mathrm{O})$ occupy four equatorial sites of the metal center. This arrangement was confirmed by a single crystal $\mathrm{X}$-ray diffraction analysis. In a similar manner, Y(III) also forms a tetracoordinated complex. However, the complex adopts a dodecahedral conformation, because of the eight-coordination fashion of Y(III) cation. It should be noted that both of the hydroxyl protons are retained in all examples of the metal complexes and that the resting coordination sites are occupied by either anions of the metal salts or molecules of solvents.

\subsection{Alkylation and Allylation of Aldehydes}

In its first application, Bolm's ligand was used in the enantioselective alkylation of aldehydes using diethylzinc as the alkylating agent [9]. With $5 \mathrm{~mol} \%$ of $(R, R)-\mathbf{1}$ in toluene at $-25^{\circ} \mathrm{C}$, the ethylation of benzaldehyde 2a yielded the secondary alcohol 3 in $94 \%$ with $97 \%$ ee (Scheme 1). In the following work, the scope of the reaction was assessed by using a wide range of aldehydes under similar reaction conditions [20]. While the aromatic aldehydes provided appropriate products in high yields and enantiomeric purities (79-97\% ee), the aliphatic aldehydes were alkylated in lower yields and enantioselectivities (16-70\% ee).

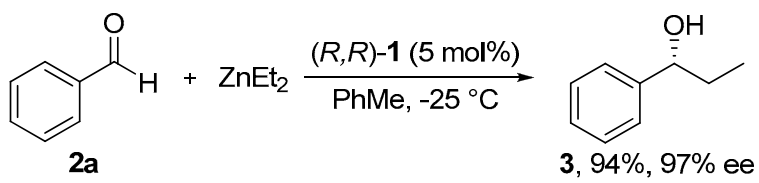

Scheme 1. Alkylation of benzaldehyde 2a.

The first examples of allylation of aldehydes were described by Kobayashi et al. in 2010 and 2011 [21,22]. Whereas the uncatalyzed allylation led predominantly to the $\gamma$-addition product 7 (Entry 1, Table 1), the one catalyzed by Zn(II) hydroxide shifted the regioselectivity towards $\alpha$-product 6 (Entry 2). The exclusive formation of $\alpha$-addition products 6 was observed when the reaction was catalyzed by a combination of Zn(II) hydroxide and Bolm's ligand (S,S)-1 (Entry 3). In addition, the syn-product was obtained predominantly with $71 \%$ ee.

Table 1. Allylation of benzaldehyde 2a.

\begin{tabular}{|c|c|c|c|c|c|c|c|c|}
\hline $2 a$ & & 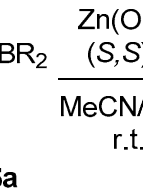 & & $\mathrm{H}$ & $\mathrm{OH}^{\mathrm{OH}}$ & & & $\begin{array}{l}\text { le } \\
5 a\end{array}$ \\
\hline Entry & 4 or $5 a$ & $\begin{array}{c}\mathrm{Zn}(\mathrm{OH})_{2} \\
(\mathrm{~mol} \%)\end{array}$ & $\begin{array}{c}(S, S)-1 \\
(\mathrm{~mol} \%)\end{array}$ & $\mathrm{MeCN} / \mathrm{H}_{2} \mathrm{O}$ & $\begin{array}{c}\text { Yield } \\
(\%)\end{array}$ & $6 / 7$ & $\underset{(\text { syn/anti) }}{\mathrm{dr}}$ & $\begin{array}{c}\text { ee }(s y n) \\
(\%)\end{array}$ \\
\hline 1 & 4 & - & - & $4 / 1$ & 77 & $5 / 95$ & - & - \\
\hline 2 & $5 a$ & 10 & - & $4 / 1$ & 86 & $45 / 55$ & $70 / 30$ & - \\
\hline 3 & $5 a$ & 10 & 12 & $7 / 3$ & 92 & $>99 / 1$ & $91 / 9$ & 71 \\
\hline
\end{tabular}

The assessment of the scope of the reaction revealed that other aldehydes are also allylated, forming exclusively $\alpha$-addition products (Table 2). 3-Phenylpropanal $\mathbf{2 b}$ was $\alpha$-(alkyl)allylated using various boronates $\mathbf{5 a - 5} \mathbf{c}$ in excellent yields and high to excellent enantioselectivity (Entries 1-3), as well as $\alpha$-chloroallylation with $\mathbf{5 d}$ proceeded smoothly with 3-phenylpropanal $\mathbf{2 b}$ (Entry 4 ), benzaldehyde 
2a (Entry 5), substituted benzaldehydes 2c and 2d (Entries 6 and 7), 1-naphthylcarbaldehyde 2e (Entry 8), and undecanal $\mathbf{2 f}$ (Entry 9). In all cases, $\alpha$-chlorohomoallylic alcohols were obtained with a selectivity higher than $93 \%$ of the syn product.

Table 2. Allylations of benzaldehydes 2 to 8 .

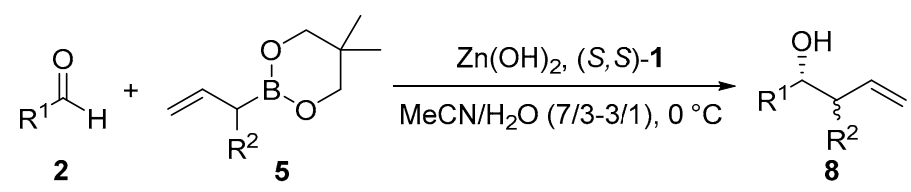

\begin{tabular}{|c|c|c|c|c|c|c|c|c|c|}
\hline Entry & $\mathbf{R}^{1}$ & & $\mathbf{R}^{2}$ & & $\begin{array}{l}\mathrm{Zn}(\mathrm{OH})_{2} \\
(\mathrm{~mol} \%)\end{array}$ & $\begin{array}{c}(S, S)-1 \\
(\mathrm{~mol} \%)\end{array}$ & $\begin{array}{c}\text { Yield } \\
(\%)\end{array}$ & $\begin{array}{c}\mathrm{dr} \\
\text { (syn/anti) }\end{array}$ & $\begin{array}{c}\text { ee }(s y n) \\
(\%)\end{array}$ \\
\hline 1 & $\mathrm{PhCH}_{2} \mathrm{CH}_{2}$ & $2 b$ & $\mathrm{Me}$ & $5 a$ & 5 & 6 & 94 & $83 / 17$ & 85 \\
\hline 2 & $\mathrm{PhCH}_{2} \mathrm{CH}_{2}$ & $2 b$ & Et & $5 b$ & 5 & 6 & 96 & $75 / 25$ & 91 \\
\hline 3 & $\mathrm{PhCH}_{2} \mathrm{CH}_{2}$ & $2 b$ & $i \mathrm{Bu}$ & $5 c$ & 5 & 6 & 95 & $75 / 25$ & 91 \\
\hline 4 & $\mathrm{PhCH}_{2} \mathrm{CH}_{2}$ & $2 b$ & $\mathrm{Cl}$ & $5 d$ & 3 & 3.6 & 92 & $93 / 7$ & 95 \\
\hline 5 & $\mathrm{Ph}$ & $2 a$ & $\mathrm{Cl}$ & $5 d$ & 5 & 6 & 92 & $96 / 4$ & 88 \\
\hline 6 & $4-\mathrm{MeC}_{6} \mathrm{H}_{4}$ & $2 c$ & $\mathrm{Cl}$ & $5 d$ & 3 & 3.6 & 91 & $96 / 4$ & 87 \\
\hline 7 & $4-\mathrm{BrC}_{6} \mathrm{H}_{4}$ & $2 d$ & $\mathrm{Cl}$ & $5 d$ & 7.5 & 9 & quant & $95 / 5$ & 85 \\
\hline 8 & 1-naphthyl & $2 e$ & $\mathrm{Cl}$ & $5 d$ & 5 & 6 & 94 & $93 / 7$ & 85 \\
\hline 9 & $\mathrm{CH}_{3}\left(\mathrm{CH}_{2}\right)_{10}$ & $2 f$ & $\mathrm{Cl}$ & $5 d$ & 2 & 2.4 & 92 & $93 / 7$ & 93 \\
\hline
\end{tabular}

The mechanism of the described allylation has not yet been completely elucidated, but the authors proposed a double $\gamma$-addition process where the boron atom is in the first step transmetallated by zinc in $\gamma$-addition fashion, while the formed allylzinc species reacts in the next step with aldehyde again by $\gamma$-addition. Some of the intermediates of the proposed mechanism were confirmed by mass spectrometry [12].

\subsection{Conjugate Addition}

Conjugate addition is one of the most frequently studied reactions with application of Bolm's ligand. The first reports were published by Bolm et al. in 1990 and 1992, respectively, and dealt with the ethylation of chalcone 9 with diethyl zinc. The ethylated product 10 was furnished in $75 \%$ yield with $72 \%$ ee, with only $1 \mathrm{~mol} \%$ of $\mathrm{Ni}(\mathrm{II})$ acetylacetonate, but $20 \mathrm{~mol} \%$ of ligand $(S, S)-1$ were required (Scheme 2) [23,24].

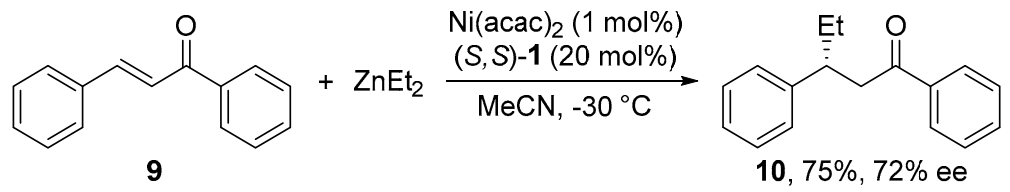

Scheme 2. Conjugate addition to enone 9.

In 2006 Kobayashi et al. published an example of Michael addition catalyzed by Sc-complex prepared from $\mathrm{Sc}(\mathrm{III})$ triflate and ligand $(S, S)-\mathbf{1}$ [25]. The study of the reaction of $\beta$-ketoester $\mathbf{1 1}$ with methyl vinyl ketone (MVK) 12 showed that the course of the reaction depended not only on the solvent used (Entries 3-6, Table 3), but also on concentration of the starting material: the lower the concentration, the higher the enantioselectivity (Entries 6-8). Regarding temperature, surprisingly, the optimal turned out to be $40^{\circ} \mathrm{C}$, while at lower temperatures both yield and enantiopurity dropped (Entries 1-3 and 8).

In 2011 two groups, Vaccaro et al. and Kobayashi et al., published independently the addition of benzyl thiol to $\alpha, \beta$-unsaturated ketone 14 catalyzed by Sc(III) triflate and Bolm's ligand 1 in water (Table 4) [26,27]. Both groups noticed that, under ambient conditions, the $\mathrm{pH}$ of the reaction mixture 
was acidic, and decided therefore to carry out the reaction in the presence of a catalytic amount of base. The former used $\mathrm{NaOH}$ (Entry 2) and the latter pyridine (Entry 3). In both instances, adducts 15 in comparable yields and enantioselectivities were obtained.

Table 3. Michael addition of $\beta$-ketoester 11 to methyl vinyl ketone (MVK) 12.

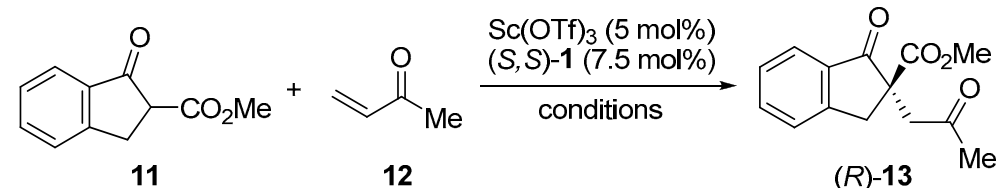

\begin{tabular}{cccccc}
\hline Entry & Solvent $^{\mathbf{1}}$ & $\mathbf{T}\left({ }^{\circ} \mathbf{C}\right)$ & $\boldsymbol{c}(\mathbf{M})$ & Yield (\%) & ee (\%) \\
\hline 1 & DCM & 10 & 0.08 & 22 & 53 \\
2 & DCM & 20 & 0.08 & 61 & 80 \\
3 & DCM & 30 & 0.08 & 98 & 81 \\
4 & PhMe & 10 & 0.08 & quant. & 5 \\
5 & MeCN/DCM & 30 & 0.08 & 76 & 8 \\
6 & DCE & 30 & 0.08 & 94 & 84 \\
7 & DCE & 30 & 0.04 & 96 & 89 \\
8 & DCE & 40 & 0.02 & 94 & 92 \\
\hline
\end{tabular}

${ }^{1}$ DCM - dichloromethane, DCE - 1,2-dichloroethane.

Table 4. Conjugate addition of benzylthiol on $\alpha, \beta$-unsaturated ketone 14 .

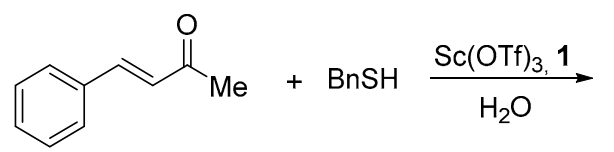

14<smiles>CC(=O)CC(Br)c1ccccc1</smiles>

15

\begin{tabular}{|c|c|c|c|c|c|c|}
\hline Entry & $\mathrm{Sc}(\mathrm{OTf})_{3}(\mathrm{~mol} \%)$ & $1(\mathrm{~mol} \%)$ & Base (mol\%) & $T\left({ }^{\circ} \mathrm{C}\right)$ & Yield (\%) & ee $(\%)$ \\
\hline 1 & 2 & $5(R, R)$ & - & 30 & 46 & $57(R)$ \\
\hline 2 & 1 & $2(R, R)$ & $\mathrm{NaOH}(3)$ & 30 & 95 & $91(R)$ \\
\hline 3 & 1 & $1.2(S, S)$ & Pyridine (10) & r.t. & 92 & $93(S)$ \\
\hline
\end{tabular}

The generality of the sulfa-Michael addition was demonstrated through the screening of various types of substrates, such as aromatic and aliphatic enones and thiols. In most cases, the reaction gave products in high to excellent yields (63-100\%) and with high enantioselectivity (76-97\% ee). The only exceptions were the additions of thiophenol that proceeded with mediocre enantioselectivity in the range of $44-52 \%$ ee. Presumably, the drop was caused by its higher acidity.

The sulfa-Michael addition of benzyl thiol to $\alpha, \beta$-unsaturated oxazolidin-2-ones catalyzed by a Fe(II)-(S,S)-1 complex has been recently studied by Ollevier et al. They used hexahydrate Fe(II) perchlorate as the Lewis acid [28]. The product $\mathbf{1 7}$ of the addition of benzyl thiol on oxazolidin-2-one 16 was isolated in $94 \%$ yield with $92 \%$ ee (Scheme 3 ).

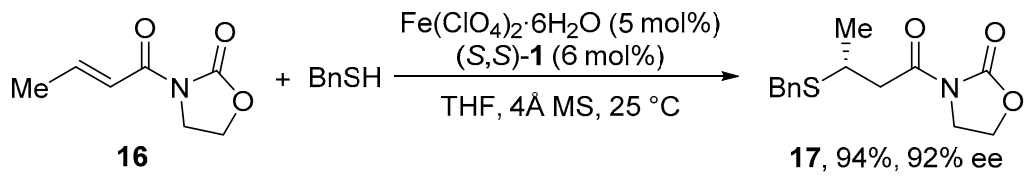

Scheme 3. Sulfa-Michael addition of benzylthiol on $\alpha, \beta$-unsaturated oxazolidin-2-one $\mathbf{1 6}$.

Another type of reaction intensively studied in Kobayashi's group was the 1,4-addition reaction of bis(pinacolato)diboron $\left(\mathrm{B}_{2}(\mathrm{pin})_{2}\right)$ catalyzed by either $\mathrm{Cu}(\mathrm{II})$ salts or $\mathrm{Cu}$ powder. The addition proceeded on various substrates such as $\alpha, \beta$-unsaturated ketones [29-31], imines [32], or nitriles [33]. 
The representative examples of this reaction are summarized in Table 5. The borylated products 18-20 were directly converted to the corresponding $\beta$-hydroxy alcohol 21-23, because of better enantiomer separation and better determination of enantiomeric excess by HPLC analysis.

Table 5. Conjugate boron addition to $\alpha, \beta$-unsaturated compounds.

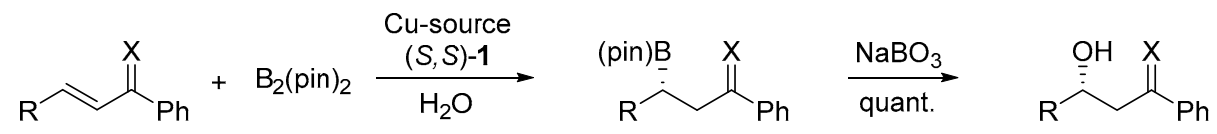

$18, \mathrm{R}=\mathrm{Ph}, \mathrm{X}=\mathrm{O}$

19, $\mathrm{R}=\mathrm{Ph}, \mathrm{X}=\mathrm{NBn}$

21, $\mathrm{R}=\mathrm{Ph}, \mathrm{X}=\mathrm{O}$

20, $\mathrm{R}=\mathrm{PhCH}=\mathrm{CH}, \mathrm{X}=\mathrm{O}$

22, $R=P h, X=N B n$

23, $\mathrm{R}=\mathrm{PhCH}=\mathrm{CH}, \mathrm{X}=\mathrm{O}$

\begin{tabular}{|c|c|c|c|c|c|c|c|c|c|}
\hline Entry & $\mathbf{R}$ & $X$ & Cu-Source & $\left(\mathrm{mol}^{\mathrm{o}} \mathrm{)}\right)$ & $\begin{array}{l}(S, S)-1 \\
(\mathrm{~mol} \%)\end{array}$ & $\begin{array}{l}\text { Additive } \\
\text { (mol\%) }\end{array}$ & $T\left({ }^{\circ} \mathrm{C}\right)$ & $\begin{array}{c}\text { Yield } \\
(\%)\end{array}$ & ee $(\%)$ \\
\hline 1 & $\mathrm{Ph}$ & $\mathrm{O}$ & $\mathrm{Cu}(\mathrm{OH})_{2}$ & 5 & 6 & $\begin{array}{c}\mathrm{AcOH} \\
(6)\end{array}$ & 5 & 95 & 99 \\
\hline 2 & $\mathrm{Ph}$ & $\mathrm{O}$ & $\mathrm{Cu}(\mathrm{OAc})_{2}$ & 5 & 6 & $\begin{array}{c}\mathrm{MeOH} \\
(100)\end{array}$ & r.t. & 92 & 92 \\
\hline 3 & $\mathrm{Ph}$ & $\mathrm{O}$ & $\mathrm{Cu}$ powder & 10 & 12 & - & 30 & 92 & 83 \\
\hline 4 & $\mathrm{Ph}$ & NBn & $\mathrm{Cu}(\mathrm{OAc})_{2}$ & 5 & 6 & - & r.t. & 91 & $>99$ \\
\hline 5 & $\mathrm{PhCH}=\mathrm{CH}$ & $\mathrm{O}$ & $\mathrm{Cu}(\mathrm{OAc})_{2}$ & 5 & 6 & - & 5 & 91 & 91 \\
\hline
\end{tabular}

Interesting results were obtained with $\alpha, \beta, \gamma, \delta$-unsaturated dienone 24 (Table 6) [34]. The 1,6-addition product $\mathbf{2 6}$ was obtained by using $\mathrm{Cu}(\mathrm{II})$ hydroxide and $(S, S)-\mathbf{1}$ without any additive (Entry 1), but upon using $\mathrm{Cu}(\mathrm{II})$ hydroxide and $(S, S)-\mathbf{1}$ with a catalytic amount of acetic acid or copper(II) acetate and (S,S)-1, 1,4-addition products $\mathbf{2 5}$ with negligible effect on enantioselectivity (Entries 2 and 3) were obtained. The authors proposed to explain these phenomena by the difference in the reaction mechanism. The plausible reaction intermediate in reactions using $\mathrm{Cu}$ (II) acetate (used as such or formed from $\mathrm{Cu}$ (II) hydroxide and acetic acid) is (pin)B-CuOAc, which is at the same time an activating and reacting agent enabling smooth 1,4-addition. In the $\mathrm{Cu}(\mathrm{II})$ hydroxide catalyzed reaction, the first copper species activates the carbonyl group, while the second copper-boron species attacks 24 via 1,6-addition. In this case, the steric hindrance of activating species is probably sterically preventing the attack of the position 4 .

Table 6. Conjugate addition of $\mathrm{B}_{2}$ (pin) $)_{2}$ to cyclic dienone 24 .

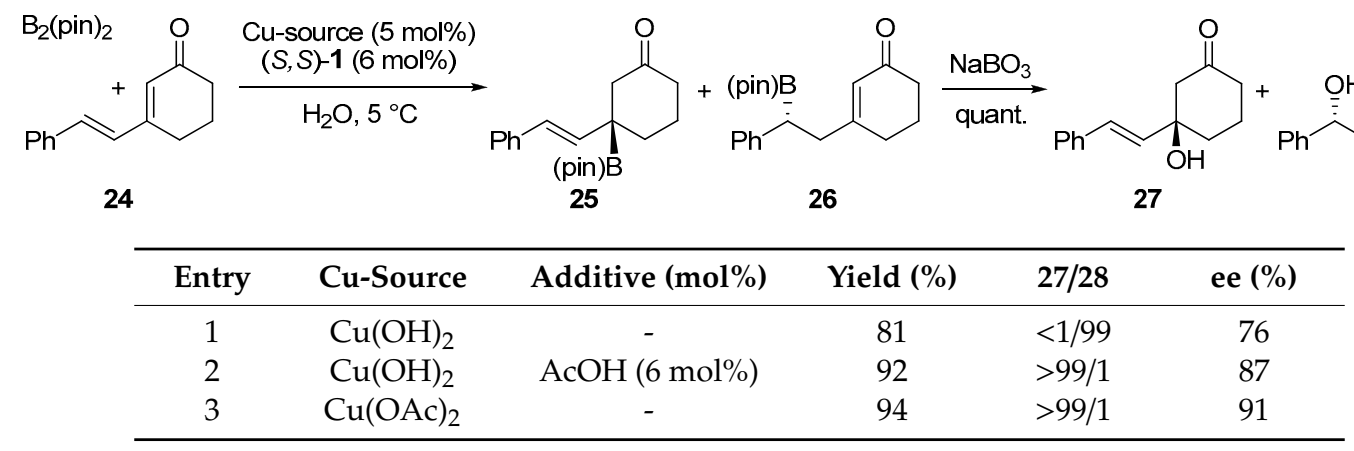

\subsection{Opening of Meso-Epoxides}

The catalytic enantioselective opening of meso-epoxides provides a powerful strategy for the formation of enantiomerically enriched products, with two contiguous chiral centers in one step from readily available achiral compounds. Since the reaction can be catalyzed by Lewis acids, the applicability of metal-1 complexes in this reaction has been intensively studied by several groups in the last two decades.

The desymmetrization of meso-epoxides by amines generally suffers from the non-compatibility of Lewis basic amine and Lewis acidic catalyst, because of their tendency to irreversibly coordinate 
to one another. Nevertheless, the aminolysis of the epoxide ring provides access to chiral $\beta$-amino alcohols, which can be found in many biologically active compounds and chiral auxiliaries. Hence, the enantioselective variant of this reaction is of considerable synthetic interest [35].

Kobayashi and Schneider et al. reported that a combination of Bolm's ligand 1 with Sc(III) triflate in DCM (Entries 1 and 3) [13,36,37], and Sc(III) dodecyl sulfate (DS) (Entry 2) [38], or undecyl sulfonate (UDST, Entry 4) [13] as "Lewis acid surfactant catalysts" (LASC) in water, exhibited high catalytic activity and enantioselectivity in the opening of meso-stilbene oxide 29 with aniline 30 (Table 7). In all cases, $\beta$-amino alcohol 35 in high to excellent yields and enantioselectivities was isolated. Interestingly, the same reaction catalyzed in the presence of copper or zinc salts provided the products with opposite configuration (Entries 5-8). The observed inversion may be caused by a different conformation of the appropriate metal complexes formed upon chelation with ligand 1. While $\mathrm{Cu}$ (II) and $\mathrm{Zn}$ (II) form tricoordinated complexes, which adopt the square-pyramidal structure, $\mathrm{Sc}$ (III) is chelated by ligand 1 in tetracoordinated manner with the pentagonal bipyramidal conformation [13]. Vaccaro et al. showed that the reaction can also be catalyzed by LASC generated in situ from Zn(II) triflate [39] or Zr(IV) chloride [40] and sodium dodecyl sulfate (Entries 9 and 10). Last but not least, the In(III) [41] and $\mathrm{Fe}(\mathrm{II})$ [16] complexes also appeared to be active Lewis acid catalysts for this reaction (Entries 11 and 12).

Table 7. Opening of epoxide ring by amine, alcohol, thiol, and selenol.

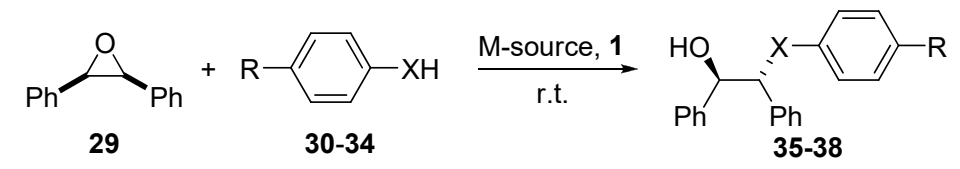

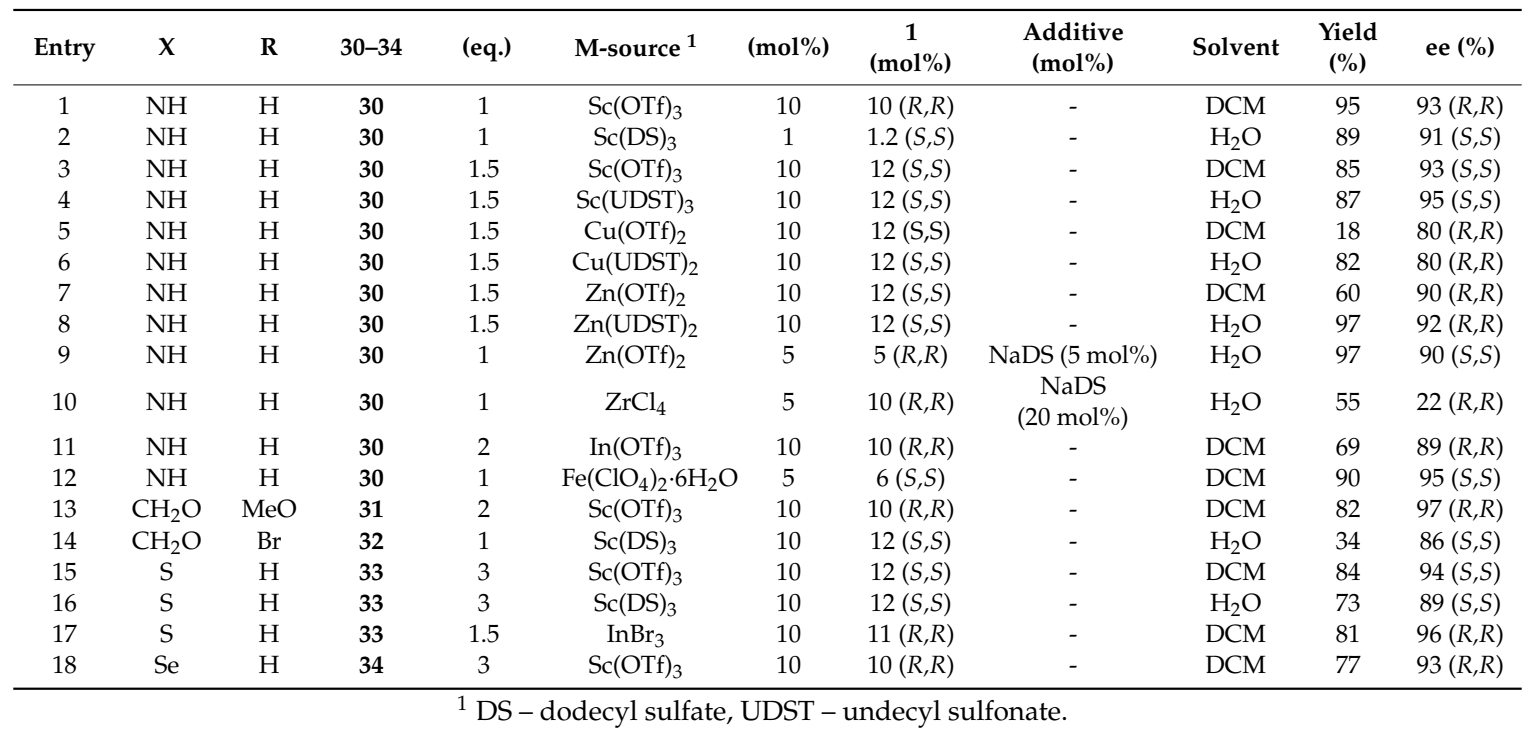

Schneider et al. and Kobayashi et al. also demonstrated the applicability of alcohols $\mathbf{3 1}$ and 32 (Entries 13 and 14) [36,42,43], thiols 33 (Entries 15-17) [19,43,44], and selenols 34 (Entry 18) [45] in the metal-catalyzed ( $\mathrm{Sc}(\mathrm{III})$ triflate and In(III) bromide) opening of the epoxide ring. The desired $\beta$-hydroxy ethers 36, sulfides 37 , and selenides 38 were obtained in moderate to high yields and high to excellent enantioselectivities. It should be noted that, because of the undesired deselenylation, the selenolyses of meso-epoxides had to be carried out in the dark and with degassed solvents.

The study of the nonlinear effect between the enantiopurity of ligand 1 and the enantiomeric excess of a product was examined in order to reveal details about the catalyst structure in the course of the reaction [13]. While the linear effect was observed in the case of a copper catalyst in DCM or in water, as well as in the case of a scandium catalyst in water, the nonlinear effect was noticed when using a scandium catalyst in DCM [46]. Interestingly, the system again evinced the linear relation when the independently preprepared complexes $\mathrm{Sc}(\mathrm{III})-(S, S)-\mathbf{1}$ and $\mathrm{Sc}(\mathrm{III})-(R, R)-\mathbf{1}$ were mixed in DCM 
with only a small excess of one of them in order to make a catalyst with low ee. The authors are assuming from these experiments that while some aggregates are formed during the mixing of Bolm's ligand $\mathbf{1}$ and $\mathrm{Sc}(\mathrm{III})$ triflate in solution, the Sc-1 complex is bound irreversibly without any possible dissociation. Despite the indisputable importance of the aminolysis of epoxides, this process under the above mentioned conditions is strictly limited to anilines.

In order to obtain the primary amino alcohols as products of opening of meso-epoxides with anilines, one would need to deprotect the $\mathrm{N}$-aryl group, which could be problematic. To overcome this, Schneider et al. developed a new approach to obtain these compounds based on the epoxide ring opening by imine 39 [47]. The products of this reaction were in the next step hydrolyzed and, because of the difficulties in the separation of highly polar 1,2-amino alcohols, protected by the Boc group (tert-butyloxycarbonyl). The product 40 was isolated in $51 \%$ yield with $80 \%$ ee after these three steps using benzophenone imine 39 (Scheme 4).

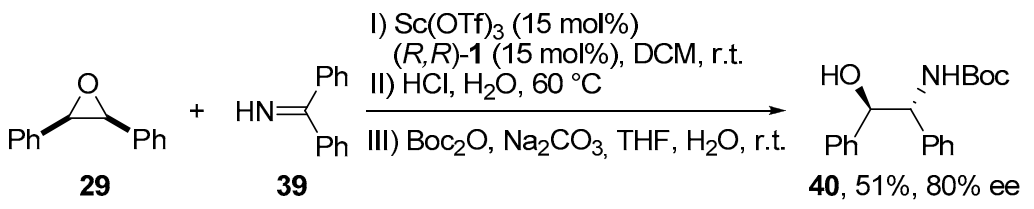

Scheme 4. Opening of epoxide 29 with benzophenone imine 39.

A great deal of attention was also paid to the opening of the epoxide ring with indole $4 \mathbf{1}$, because the indole scaffold can be found in many natural products and biologically active compounds [48]. While the reaction utilizing triflates of either Sc(III) (Entry 1, Table 8) or Zn(II) (Entry 6) in DCM provided only traces of the desired product 42 , the reaction with $\mathrm{Cu}(\mathrm{II})$ triflate yielded 43 in $60 \%$ yield with $86 \%$ ee (Entry 4). These results were even improved by using LASC based on Sc(III) (Entries 2 and 3), $\mathrm{Cu}(\mathrm{II})$ (Entry 5), or Zn(II) (Entry 7). Again, the inversion of the absolute stereochemistry of the product formed in scandium vs. copper or zinc-catalyzed reactions was observed. The best results in terms of yield and enantioselectivity were obtained with Fe(II) perchlorate (Entry 8), where the indole derivative $\mathbf{4 2}$ was obtained in $90 \%$ yield and $>99 \%$ ee.

Table 8. Opening of epoxide ring by indole.

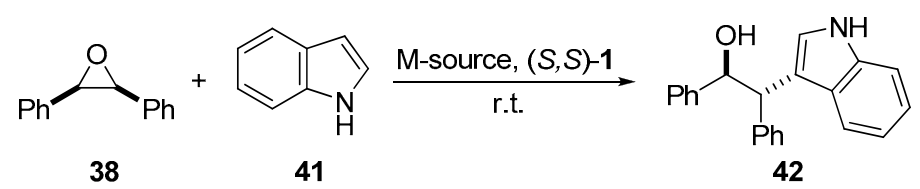

\begin{tabular}{cccccccc}
\hline Entry & $\mathbf{4 2}$ (eq.) & M-source (mol\%) & & $(\mathbf{S}, \mathbf{S}) \mathbf{- 1}(\mathbf{m o l} \%)$ & Solvent & Yield (\%) & ee (\%) \\
\hline 1 & 1.2 & $\mathrm{Sc}(\mathrm{OTf})_{3}$ & 10 & 12 & $\mathrm{DCM}$ & Traces & - \\
2 & 1.1 & $\mathrm{Sc}(\mathrm{DS})_{3}$ & 5 & 6 & $\mathrm{H}_{2} \mathrm{O}$ & 85 & $93(R, R)$ \\
3 & 1.2 & $\mathrm{Sc}(\mathrm{UDST})_{3}$ & 10 & 12 & $\mathrm{H}_{2} \mathrm{O}$ & 69 & $92(R, R)$ \\
4 & 1.2 & $\mathrm{Cu}(\mathrm{OTf})_{2}$ & 10 & 12 & $\mathrm{DCM}$ & 60 & $86(S, S)$ \\
5 & 1.2 & $\mathrm{Cu}(\mathrm{UDST})_{2}$ & 10 & 12 & $\mathrm{H}_{2} \mathrm{O}$ & 80 & $96(S, S)$ \\
6 & 1.2 & $\mathrm{Zn}(\mathrm{OTf})_{2}$ & 10 & 12 & $\mathrm{DCM}$ & Traces & - \\
7 & 1.2 & $\mathrm{Zn}(\mathrm{UDST})_{2}$ & 10 & 12 & $\mathrm{H}_{2} \mathrm{O}$ & 8 & $80(S, S)$ \\
$8^{1}$ & 1.2 & $\mathrm{Fe}\left(\mathrm{ClO}_{4}\right)_{2} \cdot 6 \mathrm{H}_{2} \mathrm{O}$ & 5 & 6 & $\mathrm{DCM}$ & 90 & $>99(R, R)$ \\
\hline
\end{tabular}

${ }^{1} 4 \AA$ MS were used as an additive.

\subsection{Mukaiyama Aldol Reaction}

Classical aldol reactions may suffer from several possible side reactions such as self-condensation, isomerization, or over-reaction. In this respect, such problems are to a large extent solved by using Mukaiyama aldol reaction conditions. The advantage stems from the fact that the above-mentioned problems are overcome by using stable enols (silyl enol ethers), and the activation of the carbonyl 
group is generally done by a Lewis acid. In addition, the use of chiral Lewis acids by a combination of a suitable metal cation and a chiral ligand allows the reaction to proceed enantioselectively.

Ollevier et al. reported in 2012 a highly enantioselective reaction of $2 \mathrm{a}$ with 43 by using $5 \mathrm{~mol} \%$ of hexahydrate $\mathrm{Fe}(\mathrm{II})$ perchlorate, $15 \mathrm{~mol} \%$ of ligand $(S, S)-\mathbf{1}$, and $6 \mathrm{~mol} \%$ of benzoic acid in a dimethoxyethane (DME)/water mixture (Scheme 5) [14]. Water was found to be essential for the reaction. In its absence, when the reaction was carried out in dry DME, the desired product was not formed. It was shown that these conditions are suitable for various types of substrates including aromatic, aliphatic, heteroaromatic, and unsaturated aldehydes providing products in high yields, diastereoselectivities, and enantioselectivities (exceeding $91 \%$ ee for all substrates).

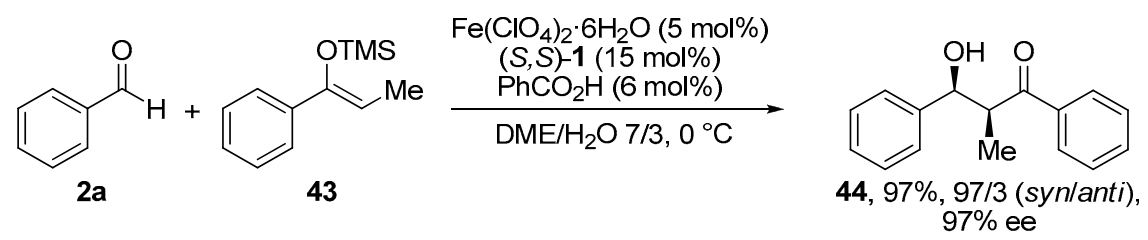

Scheme 5. Mukaiyama aldol reaction of $\mathbf{4 3}$ with 2a catalyzed by Fe(II)-(S,S)-1 complex.

On the occasion of the 40th anniversary of the discovery of the Mukaiyama aldol reaction, Ollevier and Kobayashi et al. published a detailed study on the utilization of Bolm's ligand $\mathbf{1}$ in this reaction [49]. They optimized the type of Lewis acid, additive, solvent, ligand, and their loading. They defined three typical conditions (Table 9): conditions A use Fe(II) triflate and pyridine, conditions B Fe(II) perchlorate and benzoic acid, while conditions $\mathrm{C}$ are based on $\mathrm{Bi}(\mathrm{III})$ triflate and pyridine. Conditions $\mathrm{A}$ are suitable for bulky electron-rich aldehydes. On the other hand, bulky electron-poor aldehydes in combination with silyl enol ethers with neutral or electron-withdrawing groups (EWG) are appropriate substrates for conditions B. The bulky, electron-poor aldehydes react well with silyl enol ethers with electron-donating group (EDG) under conditions $\mathrm{C}$, and are also suitable for reaction with non-bulky aldehydes.

Table 9. Optimized reaction conditions in Mukaiyama aldol reaction of silyl enol ether with aldehydes.<smiles>[R][CH-]C([R])=O</smiles>

\begin{tabular}{cccc}
\hline Silyl Enol Ether & \multicolumn{3}{c}{ Aldehyde } \\
\hline $\mathbf{R}^{\mathbf{1}}$ & $\begin{array}{c}\mathbf{R}^{\mathbf{2}}=\text { Bulky } \\
\text { Electron Rich }\end{array}$ & Electron Poor & $\mathbf{R}^{2}=$ Non-Bulky \\
\hline Neutral & A & B & C \\
EDG & A & C & C \\
EWG & A & B & C
\end{tabular}

Conditions A: Fe(OTf $)_{2}(3 \mathrm{~mol} \%),(\mathrm{S}, \mathrm{S})-\mathbf{1}(3.6 \mathrm{~mol} \%)$, pyridine $(7.2 \mathrm{~mol} \%), \mathrm{DME} / \mathrm{H} 2 \mathrm{O}$ 9/1, $0{ }^{\circ} \mathrm{C}$. Conditions B: $\mathrm{Fe}\left(\mathrm{ClO}_{4}\right)_{2}(3 \mathrm{~mol} \%),(\mathrm{S}, \mathrm{S})-\mathbf{1}(3.6 \mathrm{~mol} \%), \mathrm{PhCO}_{2} \mathrm{H}(3.6 \mathrm{~mol} \%), \mathrm{DME} / \mathrm{H} 2 \mathrm{O} 7 / 3,0{ }^{\circ} \mathrm{C}$. Conditions $\mathrm{C}: \mathrm{Bi}(\mathrm{OTf})_{3}(3 \mathrm{~mol} \%)$, $(S, S)-1(9 \mathrm{~mol} \%)$, pyridine (12 mol\%), DME $/ \mathrm{H}_{2} \mathrm{O} 9 / 1,0^{\circ} \mathrm{C}$.

The feasibility of the Mukaiyama aldol reaction catalyzed by the Fe(II)-(S,S)-1 complex was further improved by Ollevier et al. in 2014 by using LASC (Fe(II) dodecylsulfate) (Scheme 6) [50]. The product of the reaction was isolated in $80 \%$ yield with $91 / 9 \mathrm{dr}$ and $92 \%$ ee.

Morokuma et al. performed density functional theory (DFT) and artificial force-induced reaction (AFIR) studies on the system based on Fe(II) triflate and (S,S)-1, starting with benzaldehyde $\mathbf{2 a}$ and silyl enol ether 43, because the Mukaiyama aldol reaction mechanism is a matter of controversy [51]. First, the calculation indicated that a high-spin quintet state of Fe(II)-complex is thermodynamically stable, therefore operating in the whole mechanism. Second, the overall mechanism consisted of six 
steps. The free energy profile of this reaction revealed that, while the formation of a carbon-carbon bond is the selectivity-determining step, the rate-determining step of the reaction is the proton transfer from the molecule of water to the carbonyl group. Unfortunately, the role of the additive in this study is fully omitted.

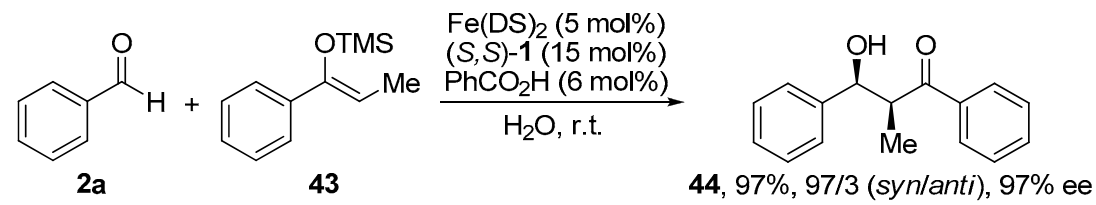

Scheme 6. Mukaiyama aldol reaction using LASC conditions.

\subsection{Hydroxymethylation}

Hydroxymethylation is a very useful transformation, allowing for the introduction of a one-carbon functional group in the $\alpha$-position of the carbonyl group by using formaldehyde. Since its reaction mechanism is close to that of the aldol reaction, similar catalytic systems could be used to promote it. Kobayashi et al. reported three studies dealing with a Lewis acid catalyzed hydroxymethylation utilizing Bolm's ligand (S,S)-1 (Table 10). In 2004, the catalysis by Sc(III) triflate in DME/water mixture at $-20^{\circ} \mathrm{C}$ (Entry 1) was reported [52], and in the following year a Bi(III) triflate catalyzed process at $0{ }^{\circ} \mathrm{C}$ was disclosed [18]. In addition, a decrease of the amount of catalyst to only $1 \mathrm{~mol} \%$ was achieved in the presence of 2,2'-bipyridine as an additive. It is assumed that its presence led to the stabilization of the Lewis acid catalytic species in the aqueous media (Entry 2). The same authors also developed conditions to execute the reaction in water. The presence of Triton ${ }^{\circledR}$ X-705 surfactant was responsible for the formation of a colloidal system (Entry 3) [53]. Under all conditions, a high stereoselectivity of $\sim 90 \%$ ee was observed.

Table 10. Hydroxymethylation of silyl enol ether 43 and 45 by formaldehyde..<smiles>[Z]OC(=CC)c1cccc([R])c1</smiles>

43, $\mathrm{R}=\mathrm{H}$

45, $\mathrm{R}=\mathrm{Me}$

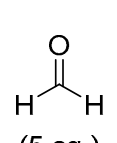

(5 eq.)

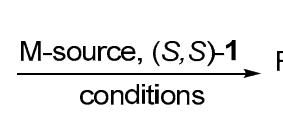<smiles>C[C@@H](CO)C(=O)c1cccc(I)c1</smiles>

46: $\mathrm{R}=\mathrm{H}$

47: $\mathrm{R}=\mathrm{Me}$

\begin{tabular}{|c|c|c|c|c|c|c|c|c|c|}
\hline Entry & $\mathbf{R}$ & M-source ${ }^{1}$ & $(\mathrm{~mol} \%)$ & $\begin{array}{l}(S, S)-1 \\
(\mathrm{~mol} \%)\end{array}$ & Additive & Solvent & $T\left({ }^{\circ} \mathrm{C}\right)$ & $\begin{array}{c}\text { Yield } \\
(\%)\end{array}$ & ee $(\%)$ \\
\hline 1 & $\mathrm{H}$ & $\mathrm{Sc}(\mathrm{OTf})_{3}$ & 10 & 12 & - & DCM & -20 & 80 & 90 \\
\hline 2 & $\mathrm{H}$ & $\mathrm{Bi}(\mathrm{OTf})_{3}$ & 1 & 3 & $\begin{array}{l}\text { 2,2'-bipyridine } \\
\quad(5 \mathrm{~mol} \%)\end{array}$ & $\mathrm{H}_{2} \mathrm{O}$ & 0 & 93 & 91 \\
\hline 3 & $\mathrm{Me}$ & $\mathrm{Sc}(\mathrm{DS})_{3}$ & 10 & 12 & $\begin{array}{l}\text { Triton }{ }^{\circledR} \\
\text { X-705 }\end{array}$ & $\mathrm{H}_{2} \mathrm{O}$ & r.t. & 73 & 90 \\
\hline
\end{tabular}

${ }^{1}$ DS - dodecyl sulfate.

\section{7. $\alpha$-Amination of $\beta$-Ketocarbonyl Compounds}

The synthesis of non-natural $\alpha$-amino acids attracts the attention of a lot of scientific groups because of their potential application in the pharmaceutical industry $[54,55]$. One of the possible ways for their preparation is the $\alpha$-amination of carbonyl compounds.

Schneider et al. were also concerned with this reaction, for which they used diethyl azodicarboxylate (DEAD) as an amination agent and a chiral copper complex derived from Cu(II) triflate and Bolm's ligand $(R, R)-\mathbf{1}$ as a catalyst [56]. The reaction of cyclic ester $\mathbf{1 1}$ under optimized conditions gave product 48 in $91 \%$ yield with $97 \%$ ee (Scheme 7 ). 


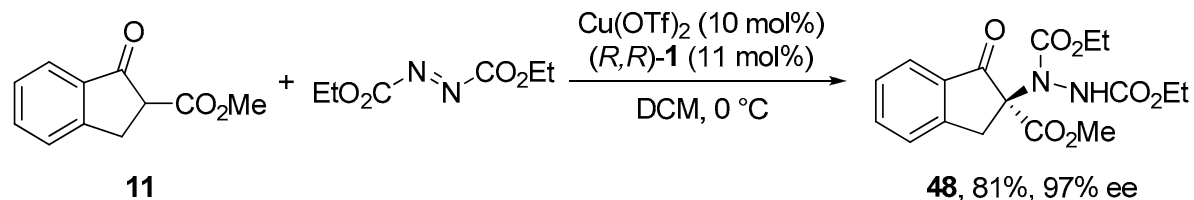

Scheme 7. $\alpha$-Amination of $\beta$-ketoester 11 with diethyl azodicarboxylate (DEAD) by $\mathrm{Cu}(\mathrm{II})-(R, R)-\mathbf{1}$ complex.

\subsection{C-H Functionalization of Indole}

The only application of Bolm's ligand $\mathbf{1}$ in the $\mathrm{C}-\mathrm{H}$ functionalization of indoles was published by Kobayashi et al. in 2016 [57]. The activation of the C3-H bond of indoles was performed by $\mathrm{Pd}(\mathrm{II})$ chloride, followed by the reaction with $\alpha, \beta$-unsaturated ketones. The reaction was carried out in water with the additive NaDS in order to stabilize the Pd(II)-indolyl intermediate, in order to increase the attractiveness of the described process from the point of view of "green chemistry". In addition, they found that the presence of water is essential for the fruitful course of the reaction, as it did not give any product in a different solvent. They also screened various organic bases and proton scavengers to prevent the undesired Brønsted acid-mediated pathway [58]. The use of either 2,6-di-tert-butylpyridine (DTBP) or N,N-dimethylaniline turned out to be optimal in terms of yield and enantioselectivity. Starting from unsubstituted indole 41 and ketone 14, the product 49 was obtained in high yields and enantiopurities $87 \%$ and $92 \%$ ee, respectively (Scheme 8 ).

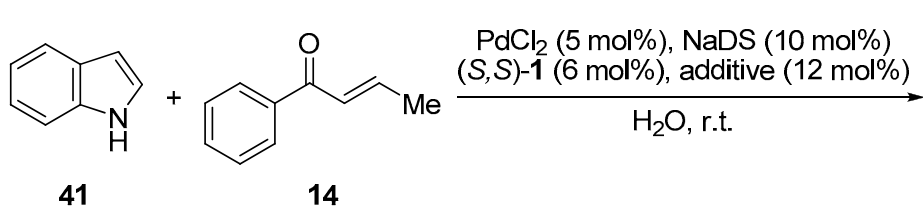

Scheme 8. C-H functionalization of indole 42 catalyzed by a $\operatorname{Pd}(\mathrm{II})-(S, S)-\mathbf{1}$ complex.

\subsection{Diels-Alder Reaction}

Most recently, Ollevier et al. reported the utilization of Bolm's ligand $\mathbf{1}$ in a Lewis acid-catalyzed Diels-Alder reaction [59]. In contrast to the already mentioned Mukaiyama aldol reaction, opening of epoxides, or Michael addition, where Fe(II) salts were compulsory for the activation of the substrate, $\mathrm{Fe}$ (III) perchlorate is optimal for high yields and selectivity of the desired products in the case of the Diels-Alder reaction. The reaction gave 52, the product of cyclization of cyclopentadiene 50 and $\alpha, \beta$-unsaturated oxazolidin-2-one 51, in quantitative yields with high 92/8 endo/exo ratio and an excellent enantioselectivity of $98 \%$ ee using only $2 \mathrm{~mol} \%$ of the Fe(III)-(S,S)-1 catalyst (Scheme 9).

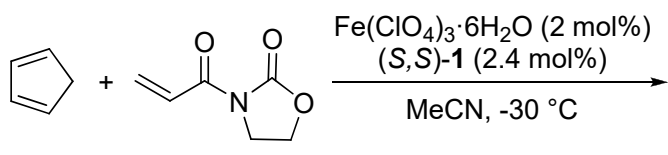

50

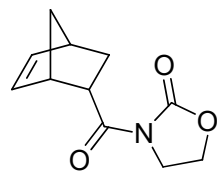

52, $99 \%, 92 / 8$ endolexo, $98 \%$ ee

Scheme 9. Diels-Alder reaction catalyzed by a Fe(III)-(S,S)-1 complex.

\subsection{Other Applications}

It should be noted that Bolm's ligand 1 was also used in a cyclopropanation reaction; however, it did not give satisfactory results, and so another ligand was used for further studies of this reaction [60]. 


\section{Conclusions}

As an examination of the known literature illustrates, Bolm's ligand possesses considerable potential to introduce chirality into prochiral substrates in various reactions. Furthermore, progress in enantioselective catalytic procedures using its combination with various metal salts still steadily continues, and it is reasonable to expect further applications. As far as its preparation is concerned, it can could be prepared with a high enantiopurity in just four steps. Hence, it is rather easily available to the chemical community for further studies.

Author Contributions: Writing and original draft preparation, E.B.; writing, review, and editing, E.B., Š.M., and M.K.; project administration, M.K.; funding acquisition, M.K. All authors have read and agreed to the published version of the manuscript.

Funding: The authors would like to acknowledge the financial support of the Czech Science Foundation (grant no. 17-07707S).

Conflicts of Interest: The authors declare no conflicts of interest.

\section{References and Note}

1. Liu, B.; Yu, W.-L.; Pei, J.; Liu, S.-Y.; Lai, Y.-H.; Huang, W. Design and Synthesis of Bipyridyl-Containing Conjugated Polymers: Effects of Polymer Rigidity on Metal Ion Sensing. Macromolecules 2001, 34, 7932-7940. [CrossRef]

2. Mathieu, J.; Fraisse, B.; Lacour, D.; Ghermani, N.; Montaigne, F.; Marsura, A. An Original Supramolecular Helicate from a Bipyridine-Bipyrazine Ligand Strand and NiII by Self-Assembly. Eur. J. Inorg. Chem. 2006, 133-136. [CrossRef]

3. Schubert, U.S.; Kersten, J.L.; Pemp, A.E.; Eisenbach, C.D.; Newkome, G.R. A New Generation of 6,6'-Disubstituted 2,2'-Bipyridines: Towards Novel Oligo (Bipyridine) Building Blocks for Potential Applications in Materials Science and Supramolecular Chemistry. Eur. J. Org. Chem. 1998, 2573-2581. [CrossRef]

4. Balzani, V.; Juris, A. Photochemistry and Photophysics of Ru (II)-Polypyridine Complexes in the Bologna Group. From Early Studies to Recent Developments. Coord. Chem. Rev. 2001, 211, 97-115. [CrossRef]

5. Margel, S.; Smith, W.; Anson, F.C. Electrochemistry of 2,2'-Bipyridine Complexes of Cobalt in the Presence of Acrylonitrile. J. Electrochem. Soc. 1978, 125, 241-246. [CrossRef]

6. Smith, A.P.; Fraser, C.L. 1.1-Bipyridine Ligands. In Comprehensive Coordination Chemistry II; McCleverty, J.A., Meyer, T.J., Eds.; Pergamon: Oxford, UK, 2003.

7. Fletcher, N.C. Chiral 2,2'-bipyridines: ligands for asymmetric induction. J. Chem. Soc. Perkin 1 2002, 1831-1842. [CrossRef]

8. Malkov, A.V.; Kocovsky, P. Chiral Bipyridine Derivatives in Asymmetric Catalysis. Curr. Org. Chem. 2003, 17, 1737-1757. [CrossRef]

9. Bolm, C.; Zehnder, M.; Bur, D. Optically Active Bipyridines in Asymmetric Catalysis. Angew. Chem. Int. Ed. Engl. 1990, 29, 205-207. [CrossRef]

10. Bolm, C.; Ewald, M.; Felder, M.; Schlingloff, G. Enantioselective Synthesis of Optically Active Pyridine Derivatives and C2-Symmetric 2,2'-Bipyridines. Chem. Ber. 1992, 125, 1169-1190. [CrossRef]

11. Ishikawa, S.; Hamada, T.; Manabe, K.; Kobayashi, S. New Efficient Method for the Synthesis of Chiral 2,2'-Bipyridyl Ligands. Synthesis 2005, 2176-2182.

12. Kobayashi, S.; Endo, T.; Yoshino, T.; Schneider, U.; Ueno, M. Allylation Reactions of Aldehydes with Allylboronates in Aqueous Media: Unique Reactivity and Selectivity That Are Only Observed in the Presence of Water. Chem. Asian J. 2013, 8, 2033-2045. [CrossRef]

13. Kokubo, M.; Naito, T.; Kobayashi, S. Chiral Zinc (II) and Copper (II)-Catalyzed Asymmetric Ring-Opening Reactions of Meso-Epoxides with Aniline and Indole Derivatives. Tetrahedron 2010, 66, 1111-1118. [CrossRef]

14. Plancq, B.; Lafantaisie, M.; Companys, S.; Maroun, C.; Ollevier, T. Highly Enantioselective Iron (II)-Catalyzed Opening Reaction of Aromatic Meso -Epoxides with Indoles. Org. Biomol. Chem. 2013, 11, 7463-7466. [CrossRef]

15. Ollevier, T.; Plancq, B. Highly Enantioselective Mukaiyama Aldol Reaction in Aqueous Conditions Using a Chiral Iron (II) Bipyridine Catalyst. Chem. Commun. 2012, 48, 2289-2291. [CrossRef] 
16. Plancq, B.; Ollevier, T. Iron (II)-Catalyzed Enantioselective Meso-Epoxide-Opening with Anilines. Chem. Commun. 2012, 48, 3806-3808. [CrossRef]

17. Kokubo, M.; Naito, T.; Kobayashi, S. Metal-Controlled Reversal of Enantioselectivity in Catalyzed Asymmetric Ring-Opening Reactions of Meso-Epoxides in Water. Chem. Lett. 2009, 38, 904-905. [CrossRef]

18. Kobayashi, S.; Ogino, T.; Shimizu, H.; Ishikawa, S.; Hamada, T.; Manabe, K. Bismuth Triflate-Chiral Bipyridine Complexes as Water-Compatible Chiral Lewis Acids. Org. Lett. 2005, 7, 4729-4731. [CrossRef]

19. Nandakumar, M.V.; Tschöp, A.; Krautscheid,H.; Schneider, C. Indium-Bipyridine-Catalyzed, Enantioselective Thiolysis of Meso-Epoxides. Chem. Commun. 2007, 2756-2758. [CrossRef]

20. Bolm, C.; Schlingloff, G.; Harms, K. Catalyzed Enantioselective Alkylation of Aldehydes. Chem. Ber. 1992, 125, 1191-1203. [CrossRef]

21. Kobayashi, S.; Endo, T.; Schneider, U.; Ueno, M. Aldehyde Allylation with Allylboronates Providing $\alpha$-Addition Products. Chem. Commun. 2010, 46, 1260-1262. [CrossRef]

22. Kobayashi, S.; Endo, T.; Ueno, M. Chiral Zinc-Catalyzed Asymmetric $\alpha$-Alkylallylation and $\alpha$-Chloroallylation of Aldehydes. Angew. Chem. Int. Ed. 2011, 50, 12262-12265. [CrossRef]

23. Bolm, C.; Ewald, M. Optically Active Bipyridines in Nickel Catalyzed Enantioselective Conjugate Addition to Enones. Tetrahedron Lett. 1990, 31, 5011-5012. [CrossRef]

24. Bolm, C.; Ewald, M.; Felder, M. Catalytic Enantioselective Conjugate Addition of Dialkylzinc Compounds to Chalcones. Chem. Ber. 1992, 125, 1205-1215. [CrossRef]

25. Ogawa, C.; Kizu, K.; Shimizu, H.; Takeuchi, M.; Kobayashi, S. Chiral Scandium Catalysts for Enantioselective Michael Reactions of $\beta$-Ketoesters. Chem. Asian J. 2006, 1, 121-124. [CrossRef]

26. Bonollo, S.; Lanari, D.; Pizzo, F.; Vaccaro, L. Sc (III)-Catalyzed Enantioselective Addition of Thiols to $\alpha, \beta$-Unsaturated Ketones in Neutral Water. Org. Lett. 2011, 13, 2150-2152. [CrossRef]

27. Ueno, M.; Kitanosono, T.; Sakai, M.; Kobayashi, S. Chiral Sc-Catalyzed Asymmetric Michael Reactions of Thiols with Enones in Water. Org. Biomol. Chem. 2011, 9, 3619-3621. [CrossRef]

28. Lauzon, S.; Keipour, H.; Gandon, V.; Ollevier, T. Asymmetric FeII-Catalyzed Thia-Michael Addition Reaction to $\alpha, \beta$-Unsaturated Oxazolidin-2-One Derivatives. Org. Lett. 2017, 19, 6324-6327. [CrossRef]

29. Kobayashi, S.; Xu, P.; Endo, T.; Ueno, M.; Kitanosono, T. Chiral Copper (II)-Catalyzed Enantioselective Boron Conjugate Additions to $\alpha, \beta$-Unsaturated Carbonyl Compounds in Water. Angew. Chem. Int. Ed. 2012, 5 , 12763-12766. [CrossRef]

30. Zhu, L.; Kitanosono, T.; Xu, P.; Kobayashi, S. A Cu (II)-Based Strategy for Catalytic Enantioselective $\beta$-Borylation of $\alpha, \beta$-Unsaturated Acceptors. Chem. Commun. 2015, 51, 11685-11688. [CrossRef]

31. Kitanosono, T.; Kobayashi, S. Asymmetric Boron Conjugate Additions to Enones in Water Catalyzed by Copper (0). Asian J. Org. Chem. 2013, 2, 961-966. [CrossRef]

32. Kitanosono, T.; Xu, P.; Isshiki, S.; Zhu, L.; Kobayashi, S. Cu (II)-Catalyzed Asymmetric Boron Conjugate Addition to $\alpha, \beta$-Unsaturated Imines in Water. Chem. Commun. 2014, 50, 9336-9339. [CrossRef]

33. Zhu, L.; Kitanosono, T.; Xu, P.; Kobayashi, S. Chiral Cu (II)-Catalyzed Enantioselective $\beta$-Borylation of $\alpha, \beta$-Unsaturated Nitriles in Water. Beilstein J. Org. Chem. 2015, 11, 2007-2011. [CrossRef]

34. Kitanosono, T.; Xu, P.; Kobayashi, S. Heterogeneous and Homogeneous Chiral Cu (II) Catalysis in Water: Enantioselective Boron Conjugate Additions to Dienones and Dienoesters. Chem. Commun. 2013, 49, 8184-8186. [CrossRef]

35. Bergmeier, S.C. The Synthesis of Vicinal Amino Alcohols. Tetrahedron 2000, 56, 2561-2576. [CrossRef]

36. Schneider, C.; Sreekanth, A.R.; Mai, E. Scandium-Bipyridine-Catalyzed Enantioselective Addition of Alcohols and Amines to Meso-Epoxides. Angew. Chem. Int. Ed. 2004, 43, 5691-5694. [CrossRef]

37. Mai, E.; Schneider, C. Scandium-Bipyridine-Catalyzed Enantioselective Aminolysis of Meso-Epoxides. Chem. Eur. J. 2007, 13, 2729-2741. [CrossRef]

38. Azoulay, S.; Manabe, K.; Kobayashi, S. Catalytic Asymmetric Ring Opening of Meso-Epoxides with Aromatic Amines in Water. Org. Lett. 2005, 7, 4593-4595. [CrossRef]

39. Bonollo, S.; Fringuelli, F.; Pizzo, F.; Vaccaro, L. Zn (II)-Catalyzed Desymmetrization of Meso-Epoxides by Aromatic Amines in Water. Synlett 2008, 1574-1578.

40. Bonollo, S.; Fringuelli, F.; Pizzo, F.; Vaccaro, L. Zr (DS)4 as an Efficient Catalyst for the Aminolysis of Epoxides in Water. Synlett 2007, 2683-2686.

41. Mai, E.; Schneider, C. Indium-Bipyridine Catalyzed, Enantioselective Aminolysis of Meso-Epoxides. Synlett 2007, 2136-2138. [CrossRef] 
42. Tschöp, A.; Marx, A.; Sreekanth, A.R.; Schneider, C. Scandium-Bipyridine-Catalyzed, Enantioselective Alcoholysis of Meso-Epoxides. Eur. J. Org. Chem. 2007, 2318-2327. [CrossRef]

43. Boudou, M.; Ogawa, C.; Kobayashi, S. Chiral Scandium-Catalysed Enantioselective Ring-Opening of Meso-Epoxides with N-Heterocycle, Alcohol and Thiol Derivatives in Water. Adv. Synth. Catal. 2006, 348, 2585-2589. [CrossRef]

44. Ogawa, C.; Wang, N.; Kobayashi, S. Chiral Scandium-Catalyzed Highly Stereoselective Ring-Opening of Meso-Epoxides with Thiols. Chem. Lett. 2007, 36, 34-35. [CrossRef]

45. Tschöp, A.; Nandakumar, M.V.; Pavlyuk, O.; Schneider, C. Scandium-Bipyridine-Catalyzed, Enantioselective Selenol Addition to Aromatic Meso-Epoxides. Tetrahedron Lett. 2008, 49, 1030-1033. [CrossRef]

46. It may seem that the results are in contrast with non-linear effect experiments on conjugate addition with $\mathrm{Sc}$ (III) triflate in water where the non-linearity was observed. On the other hand, Kobayashi et al. observed that the presence of additive can influence non-linear effect in Fe(II) catalyzed Mukaiyama aldol reaction [49]. Perhaps the use of pyridine as an additive during conjugate addition could clear up discrepancy in results.

47. Mai, E.; Schneider, C. Enantioselective Synthesis of Boc-Protected 1,2-Amino Alcohols through Aminolysis of Meso-Epoxides with Benzophenone Imine. ARKIVOC 2008, xvi, 216-222.

48. Singh, T.P.; Singh, O.M. Recent Progress in Biological Activities of Indole and Indole Alkaloids. Mini Rev. Med. Chem. 2018, 18, 9-25. [CrossRef]

49. Kitanosono, T.; Ollevier, T.; Kobayashi, S. Iron- and Bismuth-Catalyzed Asymmetric Mukaiyama Aldol Reactions in Aqueous Media. Chem. Asian J. 2013, 8, 3051-3062. [CrossRef]

50. Lafantaisie, M.; Mirabaud, A.; Plancq, B.; Ollevier, T. Iron (II)-Derived Lewis Acid/Surfactant Combined Catalysis for the Enantioselective Mukaiyama Aldol Reaction in Pure Water. ChemCatChem 2014, 6, 2244-2247. [CrossRef]

51. Sameera, W.M.C.; Hatanaka, M.; Kitanosono, T.; Kobayashi, S.; Morokuma, K. The Mechanism of Iron (II)-Catalyzed Asymmetric Mukaiyama Aldol Reaction in Aqueous Media: Density Functional Theory and Artificial Force-Induced Reaction Study. J. Am. Chem. Soc. 2015, 137, 11085-11094. [CrossRef]

52. Ishikawa, S.; Hamada, T.; Manabe, K.; Kobayashi, S. Catalytic Asymmetric Hydroxymethylation of Silicon Enolates Using an Aqueous Solution of Formaldehyde with a Chiral Scandium Complex. J. Am. Chem. Soc. 2004, 126, 12236-12237. [CrossRef]

53. Kokubo, M.; Ogawa, C.; Kobayashi, S. Lewis Acid Catalysis in Water with a Hydrophilic Substrate: Scandium-Catalyzed Hydroxymethylation with Aqueous Formaldehyde in Water. Angew. Chem. Int. Ed. 2008, 47, 6909-6911. [CrossRef] [PubMed]

54. Hodgson, D.R.W.; Sanderson, J.M. The Synthesis of Peptides and Proteins Containing Non-Natural Amino Acids. Chem. Soc. Rev. 2004, 33, 422-430. [CrossRef] [PubMed]

55. de Graaf, A.J.; Kooijman, M.; Hennink, W.E.; Mastrobattista, E. Nonnatural Amino Acids for Site-Specific Protein Conjugation. Bioconjug. Chem. 2009, 20, 1281-1295. [CrossRef] [PubMed]

56. Ghosh, S.; Nandakumar, M.V.; Krautscheid, H.; Schneider, C. Copper-Bipyridine-Catalyzed Enantioselective $\alpha$-Amination of $\beta$-Keto Esters. Tetrahedron Lett. 2010, 51, 1860-1862. [CrossRef]

57. Kitanosono, T.; Miyo, M.; Kobayashi, S. Surfactant-Aided Chiral Palladium (II) Catalysis Exerted Exclusively in Water for the C-H Functionalization of Indoles. ACS Sustain. Chem. Eng. 2016, 4, 6101-6106. [CrossRef]

58. Zhou, W.; Xu, L.-W.; Li, L.; Yang, L.; Xia, C.-G. Enantioselective Michael-Type Friedel-Crafts Reactions of Indoles to Enones Catalyzed by a Chiral Camphor-Based Brønsted Acid. Eur. J. Org. Chem. 2006, 5225-5227. [CrossRef]

59. Li, M.; Carreras, V.; Jalba, A.; Ollevier, T. Asymmetric Diels-Alder Reaction of $\alpha$, $\beta$-Unsaturated Oxazolidin-2-One Derivatives Catalyzed by a Chiral Fe (III)-Bipyridine Diol Complex. Org. Lett. 2018, 20, 995-998. [CrossRef]

60. Lee, W.-S.; Yeung, C.-T.; Sham, K.-C.; Wong, W.-T.; Kwong, H.-L. Chiral Copper-Bipyridine Complexes: Synthesis, Characterization and Mechanistic Studies on Asymmetric Cyclopropanation. Polyhedron 2011, 30, 178-186. [CrossRef]

(C) 2020 by the authors. Licensee MDPI, Basel, Switzerland. This article is an open access article distributed under the terms and conditions of the Creative Commons Attribution (CC BY) license (http://creativecommons.org/licenses/by/4.0/). 